\title{
THE INFLUENCE OF $\alpha$-LIPOIC ACID TO ENDOTHELIAL DYSFUNCTION AND ADIPOKINES BALANCE IN PATIENTS WITH TYPE 2 DIABETES AND ESSENTIAL HYPERTENSION IN THE PRESENCE OF UNFAVORABLE GENETIC POLYMORPHISM
}

${ }^{1}$ Shalimova A.S. ${ }^{2}$ Belovol A.N., ${ }^{2}$ Bobronnikova L.R., ${ }^{1}$ Kochueva M.N., ${ }^{3}$ Psareva V.G., ${ }^{3}$ Kirichenko N.N ${ }^{1}$ Kharkiv Medical Academy of Postgraduate Education, Ukraine; ${ }^{2}$ Kharkiv National Medical University, Ukraine; ${ }^{3}$ Sumy State University, Ukraine

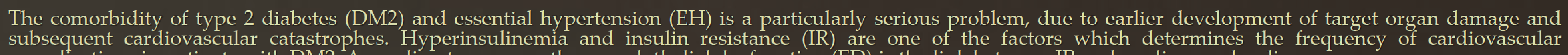
complications in patients with DM2. According to many authors, endothelial dysf The aim of this study: to establish unfavorable genetic polymorphisms on the development of comorbidity of DM2 and EH in Ukrainian population and to evaluate the effectiveness of $\alpha$-lipoic acid ( $\alpha$-LA) appointment in complex therapy in patients with 3-4 crossed unfavorable genetic polymorphisms.

Material and methods. We examined 167 patients with DM2 moderate, subcompensated and EH stage II, grade 2 .

Methods: echocardiographic evaluation of mitral diastolic blood flow and tissue Doppler spectral modes, reactive hyperemia, color Doppler mapping, biochemical blood analysis, enzyme immunoassay, spectrophotometric. Pro12Ala polymorphism of peroxisome proliferator-activated receptors- $\gamma_{2}\left(\operatorname{PPAR} \gamma_{2}\right)$, A1166C polymorphism of angiotensin II type I receptor (AGTR1) gene, Gly972Arg polymorphism of insulin receptor substrate-1 (IRS-1) gene, rs7903146 polymorphism of transcription factor 7 like 2 (TCF7L2) gene were assessed by molecular genetic method. Were identified following genotypes of $\operatorname{PPAR} \gamma_{2}$ (Pro/Pro, Pro/Ala and Ala/Ala), AGTR1 gene (A/A, A/C and C/C), IRS-1 gene (Arg/Arg, Gly/Arg and Gly/Gly), TCF7L2 gene $(\mathrm{C} / \mathrm{C}, \mathrm{C} / \mathrm{T}$ and $\mathrm{T} / \mathrm{T})$

Results and their discussion.

The primary examination of 167 patients with DM2 in combination with EH showed that $\mathrm{A} / \mathrm{C}$ and $\mathrm{C} / \mathrm{C}$ genotypes of AGTR1, Pro/Pro genotype of PPAR $\gamma_{2}$, Arg/Arg and Gly/Arg genotypes of IRS-1, T/T and C/T genotypes of TCF7L2 are characterized by more severe hemodynamic and metabolic disorders, cardiovascular remodeling, thus, these genotypes can be regarded as unfavorable genotypes that are associated with the development of comorbidity (Table 1).

Table 1

Hemodynamic and metabolic disorders in patients depending on genetic polymorphism

\begin{tabular}{|c|c|c|c|c|c|c|c|c|}
\hline \multirow{2}{*}{ Indices } & \multicolumn{2}{|c|}{ AGTR1 } & \multicolumn{2}{|c|}{$\operatorname{PPAR} \gamma_{2}$} & \multicolumn{2}{|c|}{ IRS-1 } & \multicolumn{2}{|c|}{ TCF7L2 } \\
\hline & $\mathrm{A} / \mathrm{A}$ & $\begin{array}{c}\mathrm{A} / \mathrm{C}+ \\
\mathrm{C} / \mathrm{C}\end{array}$ & $\begin{array}{c}\text { Pro/Ala }+ \\
\text { Ala/Ala }\end{array}$ & Pro/Pro & Gly/Gly & $\begin{array}{c}\text { Gly/Arg + } \\
\text { Arg/Arg }\end{array}$ & $\mathrm{C} / \mathrm{C}$ & $\mathrm{C} / \mathrm{T}+\mathrm{T} / \mathrm{T}$ \\
\hline SAP & & $\uparrow$ & & $\uparrow$ & & & & \\
\hline DAP & & $\uparrow$ & & $\uparrow$ & & & & \\
\hline EDVD & & $\downarrow$ & & $\downarrow$ & & & & \\
\hline DC & & & & $\uparrow$ & & & & \\
\hline MDA & & $\uparrow$ & & $\uparrow$ & & & & \\
\hline SOD & & $\downarrow$ & & $\downarrow$ & & & & \\
\hline catalase & & & & $\downarrow$ & & $\downarrow$ & & \\
\hline total cholesterol & & & & $\uparrow$ & & $\uparrow$ & & $\uparrow$ \\
\hline triglycerides & & & & & & $\uparrow$ & & $\uparrow$ \\
\hline LDL cholesterol & & & & & & $\uparrow$ & & $\uparrow$ \\
\hline HDL cholesterol & & $\downarrow$ & & $\downarrow$ & & & & \\
\hline blood glucose & & $\uparrow$ & & $\uparrow$ & & $\uparrow$ & & $\uparrow$ \\
\hline HbAlc & & $\uparrow$ & & $\uparrow$ & & $\uparrow$ & & $\uparrow$ \\
\hline insulin & & $\uparrow$ & & $\uparrow$ & & $\uparrow$ & & $\downarrow$ \\
\hline HOMA-IR & & $\uparrow$ & & $\uparrow$ & & $\uparrow$ & & \\
\hline adiponectin & & $\downarrow$ & & & & & & $\downarrow$ \\
\hline leptin & & $\uparrow$ & & & & $\uparrow$ & & $\downarrow$ \\
\hline
\end{tabular}

Note: $\uparrow$ - statistically significantly higher value of the indicator, $\downarrow$ - statistically significantly lower value of the indicator, SAP - systolic arterial pressure, DAP - diastolic arterial pressure, DC diene conjugates, MDA - malondialdehyde, SOD - superoxide dismutase, EDVD - endotheliumdependent vasodilatation, LDL cholesterol - low-density lipoprotein cholesterol, HDL cholesterol - high-density lipoprotein cholesterol, HbAlc - glycosylated hemoglobin, HOMA-IR - HOMA index of insulin resistance.

It was proved that in 96 patients with 3-4 crossed unfavorable genetic polymorphisms the severity of these disorders was greater than in 71 patients with 1-2 crossed unfavorable genotypes (Table 2)

Values of indicators depending on crossed unfavorable genetic polymorphisms

Table 2

\begin{tabular}{|c|c|c|}
\hline Indices & $\begin{array}{c}1-2 \text { crossed unfavorable genetic } \\
\text { polymorphisms }\end{array}$ & $\begin{array}{c}3-4 \text { crossed unfavorable genetic } \\
\text { polymorphisms }\end{array}$ \\
\hline SAP & $163,1 \pm 2,2$ & $179,7 \pm 1,9^{*}$ \\
\hline DAP & $92,4 \pm 1,8$ & $105,1 \pm 1,7^{*}$ \\
\hline EDVD & $6,7 \pm 0,07$ & $6,1 \pm 0,06^{*}$ \\
\hline DC & $38,1 \pm 1,1$ & $38,3 \pm 1,2$ \\
\hline MDA & $36,4 \pm 0,5$ & $39,9 \pm 0,4^{*}$ \\
\hline SOD & $41,6 \pm 0,6$ & $40,9 \pm 1,7$ \\
\hline catalase & $0,112 \pm 0,001$ & $0,110 \pm 0,001^{*}$ \\
\hline total cholesterol & $6,08 \pm 0,04$ & $6,5 \pm 0,03^{*}$ \\
\hline triglycerides & $2,2 \pm 0,04$ & $2,4 \pm 0,03^{*}$ \\
\hline LDL cholesterol & $4,93 \pm 0,04$ & $5,24 \pm 0,03^{*}$ \\
\hline HDL cholesterol & $0,99 \pm 0,01$ & $0,97 \pm 0,01$ \\
\hline blood glucose & $6,93 \pm 0,04$ & $7,18 \pm 0,02^{*}$ \\
\hline HbAlc & $6,96 \pm 0,04$ & $7,09 \pm 0,02^{*}$ \\
\hline insulin & $24,3 \pm 1,4$ & $25,4 \pm 1,2$ \\
\hline HOMA-IR & $7,27 \pm 0,13$ & $8,04 \pm 0,09^{*}$ \\
\hline adiponectin & $6,71 \pm 0,05$ & $6,59 \pm 0,04$ \\
\hline leptin & $15,7 \pm 0,5$ & $17,1 \pm 0,3^{*}$ \\
\hline
\end{tabular}

Among 96 patients with 3-4 crossed unfavorable genetic polymorphisms 2 groups were distinguished: 47 patients received standard therapy and 49 patients additionally received $\alpha$-LA (600 mg/day) for 3 months. It was established that the appointment of $\alpha$-LA contributed to a more pronounced effect on ED that confirmed a greater degree of endothelium-dependent vasodilation and higher levels of antioxidant system parameters (diene conjugates and malondialdehyde) in the inhibition of oxidative indicators stress (superoxide dismutase and catalase) $(p<0,001)$. Furthermore the additional appointment of $\alpha$-LA impacted more to the functioning of adipose tissue, which showed a more pronounced decrease in leptin $(p<0,001)$ and increase in adiponectin $(\mathrm{p}<0,01)$, compared to basic therapy (Figure).

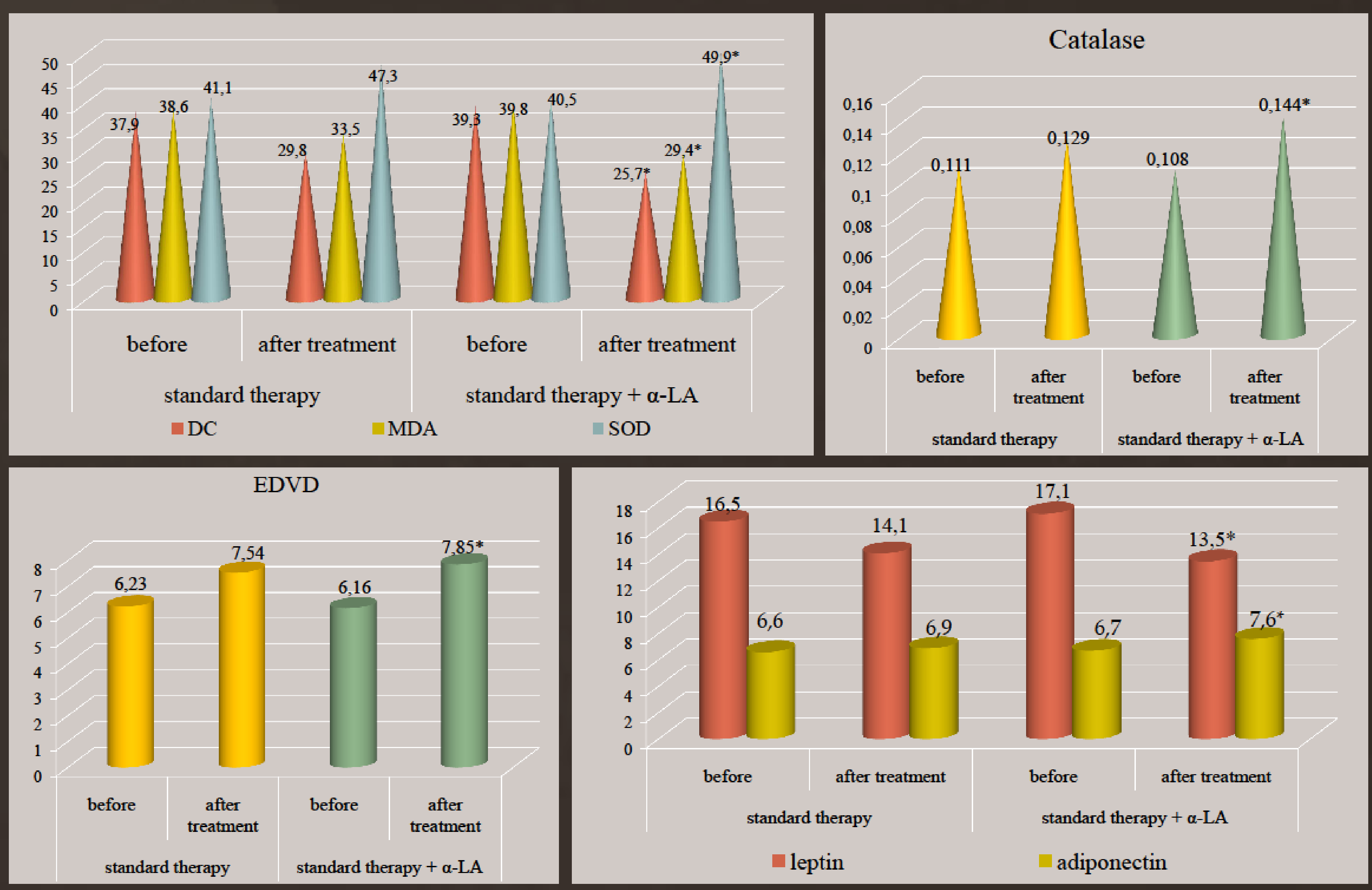

Note: * - statistically significant differences of shift indicators between standard therapy and standard therapy $+\alpha$-LA.

\section{Conclusions}

1. A/C and C/C genotypes of AGTR1, Pro/Pro genotype of PPAR $\gamma_{2}, \operatorname{Arg} / \operatorname{Arg}$ and Gly/Arg genotypes of IRS-1, T/T and C/T genotypes of TCF7L2 are associated with the development of comorbidity of DM2 and EH.

2. The additional $\alpha$-LA appointment to standard therapy impacted more to the severity of ED and adypokines balance than basic therapy

\section{References}

1. Ahluwalia T. S., Allin K. H., Sandholt C. H. et al. Discovery of coding genetic variants influencing diabetes-related serum biomarkers and their impact on risk of type 2 diabetes. Journal of

2. Ansar H.,

3. De Oliveira A. M., Rondó P. H., Luzia L. A. et al. The effects of lipoic acid and $\alpha$-tocopherol supplementation on the lipid profile and insulin sensitivity of patients with type 2 diabetes mellitus: a randomized, doubleblind, placebo-controlled trial. Diabetes Res. Clin. Pract., 2011; 92 (2): 253-260. doi:10.1016/j.diabres.2011.02.010.

4. Golbidi S., Bat M. L

5. Heinisch B. B., Francesconi M., Mittermayer F. et al. Alpha-lipoic acid improves vascular endothelial function in patients with type 2 diabetes: a placebo-controlled randomized trial. Eur. J. Clin.

5. Heinisch B. B., Francesconi M., Mittermayer F. et al. Alpha-lip.

6. Rhee E. P., Ho J. E., Chen M. H. et al. A Genome-wide Association Study of the Human Metabolome in a Community-Based Cohort. Cell Metabolism, $2013 ; 18$ (1): 130-143.

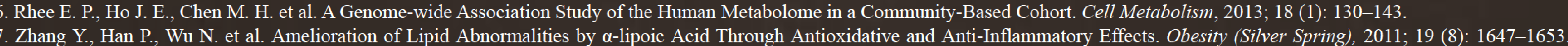

7. Zhang Y., Han P., Wu N.
doi:10.1038/oby.2011.121. 